\title{
Pemanfaatan Panas Buang Atap Seng dengan Menggunakan Generator Termoelektrik sebagai Sumber Energi Listrik Terbarukan
}

\author{
Aby Elsa Putra*, Rifky, Agus Fikri \\ Program Studi Teknik Mesin, Fakultas Teknik \\ Universitas Muhammadiyah Prof. DR. HAMKA \\ Jl. Tanah Merdeka No. 6, Kp. Rambutan, Pasar Rebo, Jakarta Timur \\ Telp. 021-87782739, Fax. 021-840091, Mobile +6289660748605 \\ *E-mail: abyelsaputra@gmail.com
}

\begin{abstract}
This research was conducted to utilize waste heat energy zinc roof for a revamped into a source of electrical energy. Waste heat utilization of zinc using thermoelectric generator type of TEC12706 to convert thermal energy into electrical energy and the fan with speed $5 \mathrm{~m} / \mathrm{s}$ to hold a low temperature in a cold area of heatsink. This research was conducted using a test simulation tool made by zinc, aluminum and acrilic. Waste heat utilization of testing zinc roof done starting at $09.00 \mathrm{WIB}$ until 15.00 WIB for 3 days, with some measured parameters required as the intensity of solar radiation $(E s)$, airspeed $(v)$, current $(I)$, power $(W)$ and temperature $(T)$ some of which are found in the system tools of simulation testing. From the results of testing performed, the value of the highest efficiency i.e. of 0,00888\% and the largest electrical power generated in the amount of 0,0042 W. A high intensity of the solar radiation it will affect the temperature of the environment which will also have an effect on the temperature in the cold area of heatsink, then the value of the temperature difference will also be affected. Heat resistance value on the system also affects the value of the waste heat energy can be changed into electrical energy.
\end{abstract}

Keyword: Heat Waste Energy, Thermoelectric Generator, Intensity of Solar Radiastion, Thermal Resistance

\section{Pendahuluan}

Pengembangan energi terbarukan di Indonesia untuk menggantikan energi konvensional ditandai dengan banyak pengembangan energi alternatif untuk menggantikan energi konvensional, seperti pembangunan PLTU, PLTS, dan PLTA yang menggantikan pembangkit listrik berasal dari bahan bakar minyak dan batu bara. Namun pada pengaplikasiannya pembuatan pembangkit listrik memerlukan biaya yang cukup besar. Sehingga tidak semua orang dapat membuat pembangkit listrik sendiri. Dengan demikian munculah berbagai inovasi kreatif yang dibuat untuk memaksimalkan berbagai sumber energi yang dapat dirubah atau dikonversi menjadi energi listrik.

Di Indonesia ada suatu permasalahan yang biasanya terdapat pada rumah, yaitu penggunaan seng sebagai atap rumah. Permasalahannya adalah energi panas yang diterima oleh seng dari matahari akan diteruskan ke dalam ruangan di bawahnya. Hal itu menyebabkan mengapa rumah yang menggunakan seng akan terasa lebih panas dibanding dengan rumah yang menggunakan genteng dari tanah liat[1]. Biasanya masyarakat akan menganggulangi permasalahan tersebut dengan memasang plafon untuk meredam panas agar tidak masuk keruangan bawah[2].

Atas dasar adanya permasalahan tersebut maka dalam penelitian ini dilakukan untuk memanfaatkan energi panas yang terdapat dalam ruangan plafon tersebut. Metode yang digunakan adalah dengan cara menyerap panas tersebut ke dalam heatsink kemudian merubahnya menjadi energi listrik dengan bantuan generator termoelektrik tipe TEC-12706. Salah satu sisi area dingin menggunakan fan untuk mengalirkan udara dengan kecepatan $5 \mathrm{~m} / \mathrm{s}$ untuk menurunkan temperatur pada area dingin

\section{Dasar Teori \\ 2.1 Radiasi Surya}

Radiasi surya merupakan suatu energi per satuan luas yang dikeluarkan oleh matahari. Energi yang dipancarkan tersebut berbentuk radiasi elektromagnetik. Radiasi yang dapat diserap oleh bumi (radiasi surya global) hanya sekitar 50\% dari total besaran konstanta matahari sebesar $1353 \mathrm{~W} / \mathrm{m} 2$. Energi radiasi matahari mempunyai besaran yang tetap (konstan), tetapi hal tersebut dapat berubah seiring dengan revolusi bumi yang mengelilingi matahari. Konstanta matahari tersebut bervariasi antara 1308 W/m2 sampai $1398 \mathrm{~W} / \mathrm{m}^{2}$ [3]. Penentuan besaran energi radiasi matahari yang diterima oleh permukaan bumi dapat dicari dengan menggunakan persamaan:

$$
\mathrm{E}_{\mathrm{s}}=\sigma \cdot \pi \cdot \mathrm{d}_{\mathrm{s}}^{2} \cdot \mathrm{T}_{\mathrm{s}}^{4}
$$

Dimana, $\sigma$ merupakan konstanta Stefan-Boltzmann yang besarnya $5,667 \times 10^{-8} \mathrm{~W} / \mathrm{m}^{2} \cdot \mathrm{K}^{4}[4]$. Dalam penyerapan 
intensitas radiasi matahari pada suatu material dapat dihitung menggunakan persamaan[5].

$$
\mathrm{I}_{\mathrm{eff}}=\mathrm{I} \cdot \alpha \cdot \mathrm{A}=\mathrm{q}_{\mathrm{konduksi}}+\text { heatloss }
$$

\subsection{Karakteristik Bahan}

\section{Seng}

Tabel 1 Sifat-sifat Seng $(\mathrm{Zn})$

\begin{tabular}{|c|c|c|c|}
\hline \multicolumn{4}{|c|}{ Sifat pada $\mathbf{2 0}^{\mathbf{0}} \mathbf{C}$} \\
\hline $\boldsymbol{\rho}\left(\mathbf{k g} / \mathbf{m}^{2}\right)$ & $\begin{array}{c}\mathbf{c}_{\mathbf{p}} \\
\left(\mathbf{k j} / \mathbf{k g} .{ }^{\circ} \mathbf{C}\right)\end{array}$ & $\mathbf{k}\left(\mathbf{W} / \mathbf{m} \cdot{ }^{\mathbf{0}} \mathbf{C}\right)$ & $\begin{array}{c}\mathbf{a} \\
\left(\mathbf{m}^{2} / \mathbf{s}\right) \mathbf{x} \mathbf{~ 1 0}^{\mathbf{5}}\end{array}$ \\
\hline 7,144 & 0,3843 & 112,2 & 4,106 \\
\hline
\end{tabular}

Sumber: Heat tranfer tenth edition (J.P Holman, 2010)

2. Aluminium

\begin{tabular}{|c|c|c|c|}
\multicolumn{4}{|c|}{ Tabel 2 Sifat-sifat Seng $(\mathrm{Zn})$} \\
\hline $\boldsymbol{\rho}\left(\mathbf{k g} / \mathbf{m}^{\mathbf{2}}\right)$ & $\mathbf{c}_{\mathbf{p}}\left(\mathbf{k j} / \mathbf{k g} .{ }^{\circ} \mathbf{C}\right)$ & $\mathbf{k}\left(\mathbf{W} / \mathbf{m} \cdot{ }^{\mathbf{}} \mathbf{C}\right)$ & $\begin{array}{c}\mathbf{a} \\
\left(\mathbf{m}^{2} / \mathbf{s}\right) \mathbf{x} \mathbf{1 0}\end{array}$ \\
\hline 2,707 & 0,896 & 204 & 8,418 \\
\hline
\end{tabular}

Sumber: Heat tranfer tenth edition (J.P Holman, 2010)

\subsection{Generator Termoelektrik}

Termoelektrik adalah alat yang digunakan untuk mengkonversi langsung dari suatu perbedaan temperatur menjadi tegangan listrik atau sebaliknya[6]-[8]. Elemen termoelektrik terdiri dari semikonduktor tipe $\mathrm{N}$ dan tipe $\mathrm{P}$ yang bagian atas dan bawah dilapisi dengan konduktor tembaga sebagai penghubung satu sama lain antara tipe $\mathrm{N}$ dan tipe $\mathrm{P}[9]$. Dalam penelitian ini modul termoelektrik yang digunakan adalah modul termoelektrik TEC1 12706. Modul termoelektrik jenis termoelektrik cooler dengan 127 pasang semikonduktor. Berikut ini adalah spesifikasi dari modul termoelektrik TEC1 12706[6]:

1. Ukuran sisi $40 \mathrm{~mm} \times 40 \mathrm{~mm}$ dengan tebal $3,8 \mathrm{~mm}$.

2. Perbedaan temperatur sisi panas dengan sisi dingin maksimal ( $\Delta$ Tmaks) sebesar $66^{\circ} \mathrm{C}$.

3. Arus listrik maksimal yang diperbolehkan (Imaks) sebesar 6 Ampere.

4. Tegangan listrik maksimal yang diperbolehkan (Vmaks) sebesar 14,4 Volt.

5. Material keramik electrical insulator yang dipergunakan adalah Aluminia $\left(\mathrm{Al}_{2} \mathrm{O}_{3}\right)$.

6. Temperatur maksimal dalam penggunaannya sebesar $138{ }^{\circ} \mathrm{C}$.

\subsection{Heatsink}

Heatsink adalah alat yang digunakan untuk menghasilkan nilai gradien termal. Dalam penggunaannya, heatsink berfungsi untuk mengalirkan energi panas atau dingin yang dibutuhkan oleh generator termoelektrik untuk menghasilkan energi listrik. Heatsink terbuat dari logam aluminium. Heatsink memiliki sirip sirip yang berfungsi untuk memperbesar laju perpindahan energi yang dibutuhkan[10], [11].

\subsection{Perpindahan Panas}

Perpindahan panas atau heat transfer adalah ilmu untuk mempetakan perpindahan energi yang terjadi karena adanya perbedaan temperatur di antara benda atau material. Perpindahan panas dalam keadaan nyata terbagi menjadi 3 jenis yaitu konduksi, konveksi dan radiasi[12].

\section{Konduksi}

Konduksi adalah perpindahan kalor melalui zat padat. Perpindahan ini tidak diikuti dengan perpindahan partikel perantara.

$$
\mathrm{q}=-\mathrm{K} \cdot \mathrm{A} \cdot \frac{\Delta T}{\Delta X}
$$

2. Konveksi

Konveksi adalah perpindahan panas dari suatu tempat ke tempat lain karena adanya perpindahan fluida, proses perpindahan panas melalui perpindahan massa.

$$
\mathrm{q}=\text { h.A. } \Delta \mathrm{T}
$$

3. Radiasi

Radiasi adalah perpindahan panas yang terjadi karena pancaran/sinaran/radiasi gelombang eletromagnetik, tanpa memerlukan media perantara.

$$
q=\varepsilon . \sigma \cdot A \cdot T^{4}
$$

\subsection{Listrik}

Listrik dapat diartikan sebagai suatu daya yang muncul akibat terjadinya suatu gesekan atau dikarenakan sebab lain seperti proses kimia[13], [14].

\section{Tegangan Listrik}

Tegangan listrik adalah perbedaan potensial listrik antara dua titik dalam rangkaian listrik. Tegangan listrik merupakan ukuran beda potensial yang mampu membangkitkan medan listrik sehingga menyebabkan timbulnya arus listrik dalam sebuah konduktor listrik[13].

$$
\mathrm{V}=\mathrm{I} \text {. R }
$$

\section{Arus Listrik}

Arus listrik adalah aliran bermuatan listrik. Aliran ini berupa aliran electron atau aliran ion. Aliran ini mengalir melalui media penghantar listrik yang disebut konduktor[13].

$$
\mathrm{I}=\frac{Q}{t}
$$

3. Daya Listrik

Daya listrik atau electrical power adalah jumlah energi yang diserap atau dihasilkan dalam sebuah sirkuit/rangkain[13].

$$
\mathrm{P}=\mathrm{V} \times \mathrm{I}
$$

\section{Metodologi Penelitian}

\subsection{Tempat dan Waktu Penelitian}

Penelitian dilakukan di Fakultas Teknik Universitas Muhammadiyah Prof. DR. HAMKA Lt. 5 Jl. Tanah 
Merdeka No. 6, Kp. Rambutan, Ps. Rebo, Jakarta Timur mulai bulan Maret sampai dengan September 2018.

\subsection{Desain Penelitian}

Desain penelitian yang digunakan dalam penelitian ini adalah penelitian eksperimental. Parameter yang digunakan adalah parameter kontrol dan parameter yang diberi perlakuan (treatment). Penelitian ini dilakukan dengan menggunakan alat simulasi pengujian seperti pada gambar berikut:

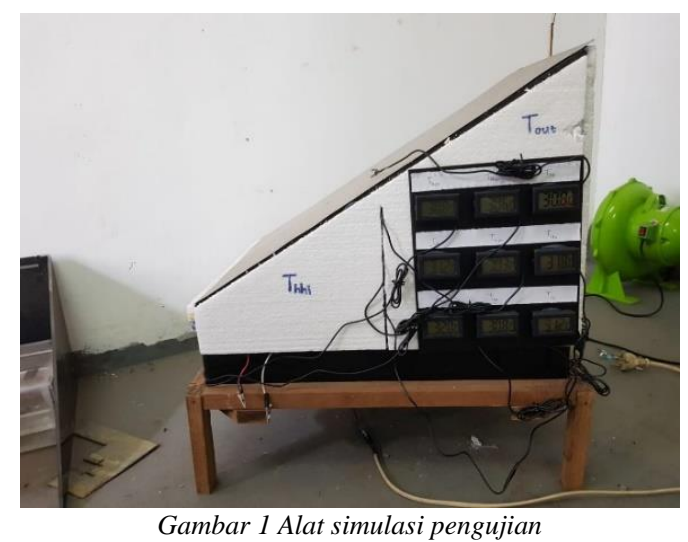

\subsection{Alat dan Bahan yang digunakan}

1. Alat

Alat yang digunakan dalam penelitian ini adalah:
a. Temometer digital
b. Solar power meter
c. Multimeter digital
d. Generator termoelektrik
e. Fan ukuran $12 \mathrm{~cm} \mathrm{x} 12 \mathrm{~cm}$
f. Anemometer

2. Bahan

Bahan yang digunakan dalam penelitian ini adalah;
a. Heat sink (300 mm x $120 \mathrm{~mm}) 18$ buah
b. Acrylic $(1200 \mathrm{~mm} \times 2440 \mathrm{~mm})$
c. Styrofoam $(600 \mathrm{~mm} \times 400 \mathrm{~mm}) 3$ buah
d. Atap seng $(90 \mathrm{~cm} \times 36 \mathrm{~cm}) 1$ buah
e. Lembaran busa $(460 \mathrm{~mm} \times 370 \mathrm{~mm})$

\subsection{Metode pengambilan dan pengumpulan data}

Penelitian ini dilakukan dengan mengunakan metode pengujian percobaan yang dilakukan selama 3 hari. Percobaan yang dilakukan dalam penelitian ini, yaitu dengan melakukan percobaan pengambilan data selama 3 hari, dengan hasil akhir mengambil nilai rata rata daya yang dihasilkan perharinya. Beberapa data yang dicari dalam peneltian ini sebagai berikut:

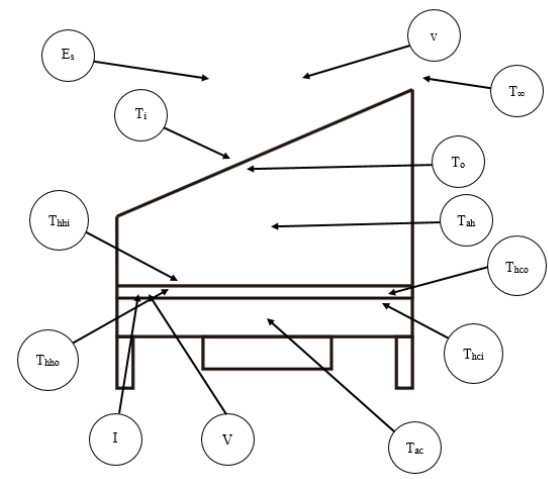

Gambar 2 Skema pengambilan data

Keterangan:

$\mathrm{t} \quad=$ waktu pengujian

$\mathrm{T}_{\mathrm{i}} \quad=$ temperatur masuk $\left({ }^{\circ} \mathrm{C}\right)$

$\mathrm{T}_{\mathrm{o}} \quad=$ temperatur keluar $\left({ }^{\circ} \mathrm{C}\right)$

$\mathrm{E}_{\mathrm{s}} \quad=$ intentitas radiasi matahari $\left(\mathrm{W} / \mathrm{m}^{2}\right)$

$\mathrm{T}_{\infty}=$ temperatur lingkungan $\left({ }^{\circ} \mathrm{C}\right)$

$\mathrm{T}_{\mathrm{ah}}=$ temperatur area bawah atap seng $\left({ }^{\circ} \mathrm{C}\right)$

$\mathrm{T}_{\text {hhi }}=$ temperatur heatsink sisi panas masuk $\left({ }^{\circ} \mathrm{C}\right)$

$\mathrm{T}_{\text {hho }}=$ temperatur heatsink sisi panas keluar $\left({ }^{\circ} \mathrm{C}\right)$

$\mathrm{T}_{\mathrm{hci}}=$ temperatur heatsink sisi dingin masuk $\left({ }^{\circ} \mathrm{C}\right)$

$\mathrm{T}_{\mathrm{hco}}=$ temperatur heatsink sisi dingin keluar $\left({ }^{\circ} \mathrm{C}\right)$

$\mathrm{T}_{\mathrm{ac}}=$ temperatur area sisi dingin $\left({ }^{\circ} \mathrm{C}\right)$

$\mathrm{V} \quad$ = tegangan $(\mathrm{V})$

$\mathrm{I}=\operatorname{arus}(\mathrm{A})$

$\mathrm{v} \quad=$ kecepatan $\operatorname{angin}(\mathrm{m} / \mathrm{s})$

Proses yang terjadi dalam alat simulasi pengujian dimulai saat intensitas radiasi matahari diserap oleh atap seng. Selanjutnya, energi panas yang diterima oleh atap seng akan ditransmisikan ke area bawah atap seng dan meningkatkan temperatur ruang tersebut. Temperatur pada ruangan tersebut akan diserap oleh heatsink dan ditransmisikan kembali ke sisi bawah heatsink yang bersentuhan langsung dengan salah satu sisi dari generator termoelektrik yang menyerap energi panas. Disisi lain generator termoelektrik, energi dingin yang diserap berasal dari heatsink yang di jaga temperaturnya menggunakan fan dengan kecepatan $5 \mathrm{~m} / \mathrm{s}$. Perbedaan temperatur dari kedua sisi generator termoelektrik akan menghasilkan energi listrik berupa tegangan dan arus listrik.

\subsection{Diagram Alir Penelitian}

Diagram alir dalam penelitian ini dibuat untuk mengetahui setiap kegiatan yang dilakukan pada awal hingga akhir penelitian, seperti yang ditunjukkan pada Gambar 3 yaitu: 


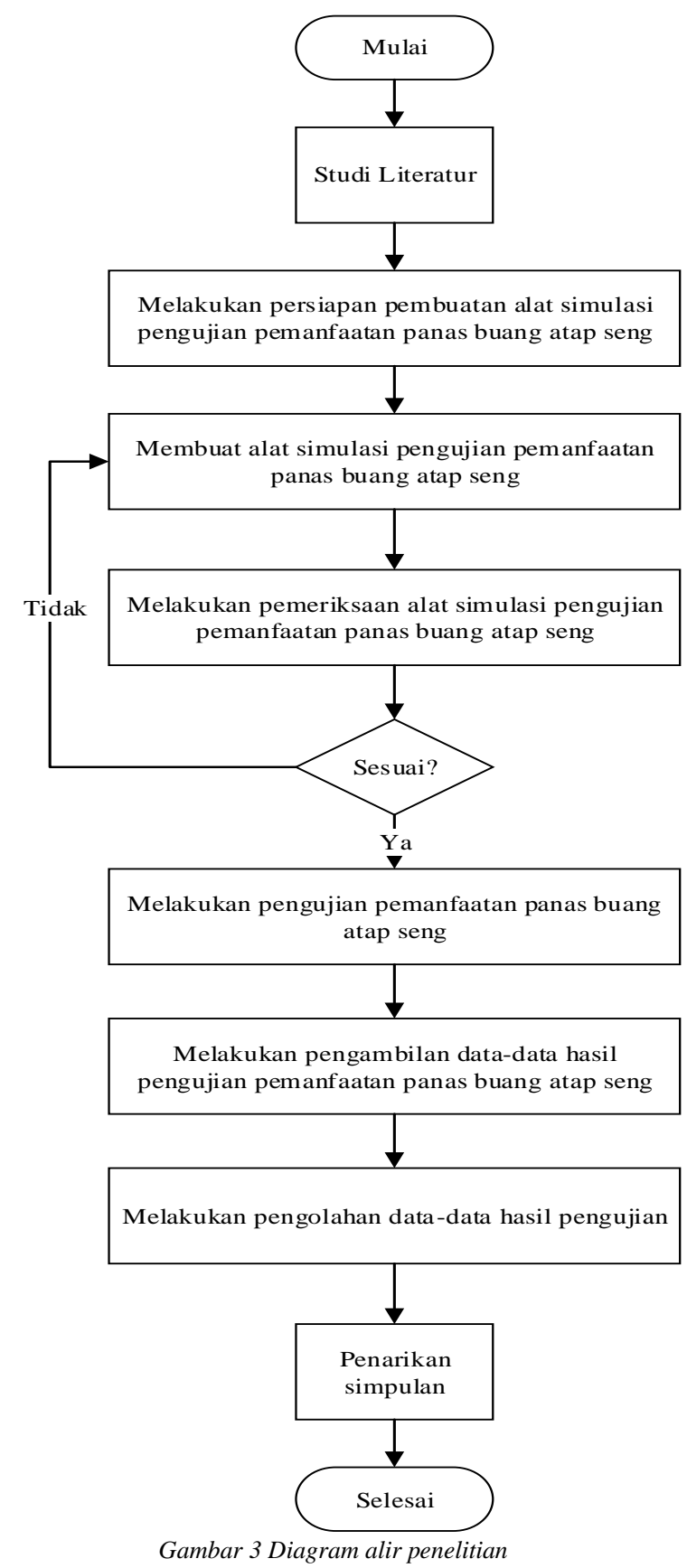

4. Temuan dan Pembahasan

\subsection{Teтuan}

Dalam pengujian ini didapatkan hasil pengolahan data selama tiga hari yang mencakup nilai perbedaan temperatur $(\Delta \mathrm{T})$, daya listrik $(\mathrm{P})$, intensitas radiasi matahari yang diserap oleh seng $\left(\mathrm{I}_{\text {eff }}\right)$ dan efisiensi ( $\mathrm{\eta}$ ) sebagai berikut:

\section{Pengolahan data hari pertama}

Tabel 3 Pengolahan data hari pertama

\begin{tabular}{|c|c|c|c|c|}
\hline No. & $\Delta \mathbf{T}\left({ }^{\circ} \mathbf{C}\right)$ & $\mathbf{I}_{\text {eff }}$ (Watt) & $\begin{array}{c}\text { Daya Listrik } \\
\text { (Watt) }\end{array}$ & Efisiensi $\mathbf{\eta}$ (\%) \\
\hline 1 & $-0,2$ & 0 & 0 & 0 \\
\hline 2 & $-0,6$ & 132,924 & 0 & 0 \\
\hline 3 & $-0,4$ & 163,719 & 0 & 0 \\
\hline 4 & 0 & 164,348 & 0 & 0 \\
\hline 5 & 0,3 & 157,906 & 0,0008 & 0,00051 \\
\hline 6 & 0,8 & 168,747 & 0,0025 & 0,00148 \\
\hline 7 & 1,4 & 160,420 & 0,0037 & 0,00231 \\
\hline 8 & 1,4 & 172,989 & 0,0036 & 0,00208 \\
\hline 9 & 1,1 & 166,861 & 0,0028 & 0,00168 \\
\hline 10 & 1,8 & 47,2931 & 0,0042 & 0,00888 \\
\hline 11 & 1,2 & 88,4586 & 0,0028 & 0,00317 \\
\hline 12 & 1 & 141,722 & 0,0025 & 0,00176 \\
\hline 13 & 1,1 & 145,964 & 0,0025 & 0,00171 \\
\hline 14 & 1,1 & 51,6925 & 0,0029 & 0,00561 \\
\hline 15 & 0,9 & 81,7024 & 0,0025 & 0,00306 \\
\hline 16 & 1,1 & 107,627 & 0,0029 & 0,00269 \\
\hline 17 & 0,7 & 101,657 & 0,0016 & 0,00157 \\
\hline 18 & 0,9 & 99,1427 & 0,0021 & 0,00212 \\
\hline 19 & 1 & 61,2768 & 0,0026 & 0,00424 \\
\hline 20 & 1 & 109,670 & 0,0025 & 0,00228 \\
\hline 21 & 0,8 & 51,5354 & 0,0018 & 0,00349 \\
\hline 22 & 0,8 & 102,442 & 0,0015 & 0,00146 \\
\hline 23 & 0,8 & 34,5664 & 0,002 & 0,00579 \\
\hline 24 & 0,7 & 49,4928 & 0,0017 & 0,00343 \\
\hline 25 & 0,3 & 129,153 & 0,0005 & 0,00039 \\
\hline
\end{tabular}

2. Pengolahan data hari kedua

Tabel 4 Pengolahan data hari kedua

\begin{tabular}{|c|c|c|c|c|}
\hline No. & $\Delta \mathbf{T}\left({ }^{\circ} \mathbf{C}\right)$ & $\mathbf{I}_{\text {eff }}$ (Watt) & $\begin{array}{c}\text { Daya Listrik } \\
\text { (Watt) }\end{array}$ & Efisiensi/ $\mathbf{\eta}$ (\%) \\
\hline 1 & 0 & 0 & 0 & 0 \\
\hline 2 & $-1,9$ & 182,259 & 0 & 0 \\
\hline 3 & $-0,9$ & 182,259 & 0 & 0 \\
\hline 4 & 0 & 172,989 & 0 & 0 \\
\hline 5 & 0,3 & 188,701 & 0,0005 & 0,00026 \\
\hline 6 & 0,3 & 190,901 & 0,0006 & 0,00031 \\
\hline 7 & 0,4 & 186,187 & 0,0007 & 0,00038 \\
\hline 8 & 0,3 & 186,973 & 0,0005 & 0,00027 \\
\hline 9 & 0,7 & 184,616 & 0,001 & 0,00054 \\
\hline 10 & 0,6 & 191,686 & 0,0011 & 0,00057 \\
\hline 11 & 0,5 & 185,402 & 0,0008 & 0,00043 \\
\hline 12 & 1,1 & 190,901 & 0,0017 & 0,00089 \\
\hline 13 & 0,7 & 195,3 & 0,0014 & 0,00072 \\
\hline 14 & 0,7 & 180,06 & 0,0012 & 0,00067 \\
\hline 15 & 0,7 & 176,289 & 0,0012 & 0,00068 \\
\hline 16 & 0,7 & 173,932 & 0,0013 & 0,00075 \\
\hline 17 & 1,3 & 174,246 & 0,0023 & 0,00132 \\
\hline 18 & 1,2 & 190,901 & 0,0024 & 0,00126 \\
\hline 19 & 1,3 & 178,645 & 0,0025 & 0,00139 \\
\hline 20 & 0,8 & 180,688 & 0,0015 & 0,00083 \\
\hline 21 & 1 & 172,046 & 0,0019 & 0,00110 \\
\hline 22 & 1 & 173,618 & 0,002 & 0,00115 \\
\hline 23 & 1,1 & 168,276 & 0,0022 & 0,00131 \\
\hline 24 & 0,8 & 167,333 & 0,0018 & 0,00108 \\
\hline 25 & 1 & 158,848 & 0,0021 & 0,00132 \\
\hline
\end{tabular}

3. Pengolahan data hari ketiga

Tabel 5 Pengolahan data hari ketiga

\begin{tabular}{|c|c|c|c|c|}
\hline No. & $\Delta \mathbf{T}\left({ }^{\circ} \mathbf{C}\right)$ & $\mathbf{I}_{\text {eff }}(\mathbf{W a t t})$ & $\begin{array}{c}\text { Daya Listrik } \\
\text { (Watt) }\end{array}$ & Efisiensi/n (\%) \\
\hline 1 & 0 & 0 & 0 & 0 \\
\hline 2 & $-1,3$ & 174,717 & 0 & 0 \\
\hline 3 & $-0,6$ & 182,573 & 0 & 0 \\
\hline 4 & $-0,3$ & 175,189 & 0 & 0 \\
\hline 5 & 0,1 & 184,145 & 0,0002 & 0,00011 \\
\hline 6 & 0,2 & 179,274 & 0,0004 & 0,00022 \\
\hline 7 & 0,6 & 178,645 & 0,001 & 0,00056 \\
\hline 8 & 0,5 & 192,943 & 0,0009 & 0,00047 \\
\hline 9 & 0,6 & 181,788 & 0,001 & 0,00055 \\
\hline 10 & 0,4 & 197,657 & 0,0006 & 0,00030 \\
\hline 11 & 0,8 & 169,375 & 0,0015 & 0,00088 \\
\hline 12 & 1,1 & 167,49 & 0,0023 & 0,00137 \\
\hline 13 & 1,2 & 38,6515 & 0,0028 & 0,00724 \\
\hline 14 & 0,8 & 38,8086 & 0,0021 & 0,00541 \\
\hline 15 & 0,5 & 48,393 & 0,0014 & 0,00289 \\
\hline 16 & 0,2 & 67,5616 & 0,0002 & 0,00029 \\
\hline 17 & 0,2 & 84,6877 & 0,0003 & 0,00035 \\
\hline 18 & 0,5 & 183,202 & 0,0007 & 0,00038 \\
\hline 19 & 0,5 & 185,716 & 0,0008 & 0,00043 \\
\hline 20 & 0,3 & 176,76 & 0,0005 & 0,00028 \\
\hline 21 & 0,4 & 174,403 & 0,0005 & 0,00028 \\
\hline 22 & 0,7 & 168,276 & 0,0018 & 0,00106 \\
\hline 23 & 0,9 & 151,935 & 0,0016 & 0,00105 \\
\hline 24 & 1,1 & 111,869 & 0,0022 & 0,00196 \\
\hline 25 & 1 & 128,053 & 0,0016 & 0,00124 \\
\hline
\end{tabular}


Dari hasil pengolahan data di atas, didapatkan beberapa grafik untuk menggambarkan proses terjadinya pemanfaatan panas buang atap seng, yaitu:

1. Grafik perbandingan antara perbedaan temperatur dengan intensitas radiasi matahari selama tiga hari

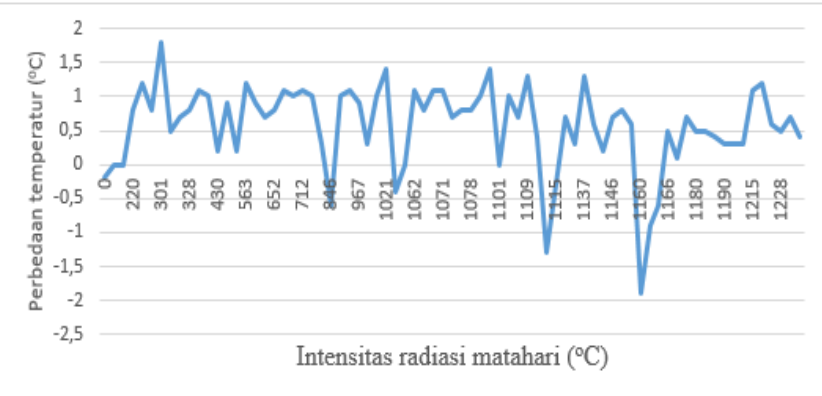

Grafik 1 Grafik perbandingan perbedaan temperatur dengan intensitas radiasi matahari tiga hari

2. Grafik perbandingan temperatur heatsink sisi panas dan sisi dingin dengan temperatur lingkungan selama tiga hari

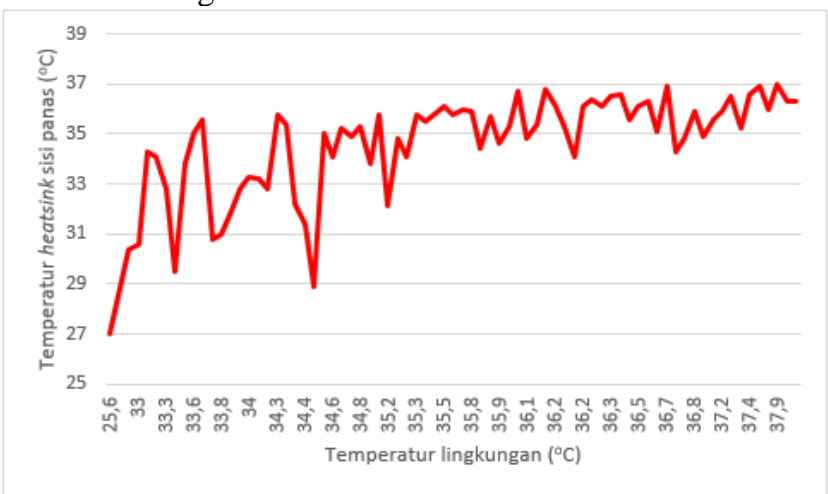

Grafik 2 Grafik perbandingan temperatur heatsink sisi panas dengan temperatur lingkungan

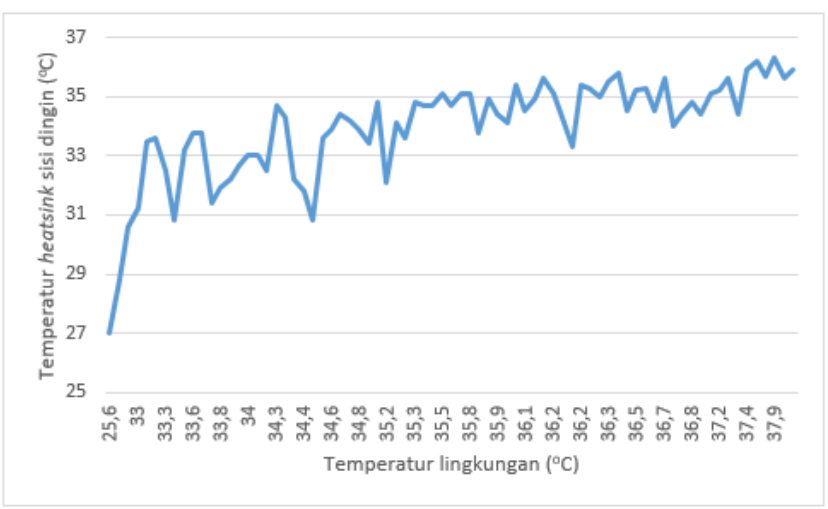

Grafik 3 Grafik perbandingan temperatur heatsink sisi dingin dengan temperatur lingkungan
3. Grafik daya listrik yang dihasilkan selama tiga hari

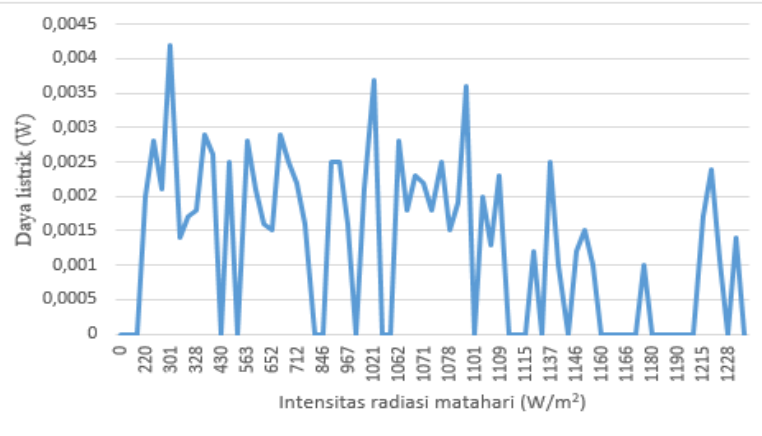

Grafik 4 Grafik daya listrik yang dihasilkan selama tiga hari

\subsection{Pembahasan}

Pada gambar 4 yang menggambarkan grafik terkait perbandingan antara intensitas radiasi matahari dengan perbedaan temperatur terdapat sebuah fenomena yang sama yang terjadi. Fenomena tersebut adalah dimana pada intensitas radiasi matahari yang sama namun menghasilkan nilai perbedaan temperatur yang bervariasi. Dari hasil pengamatan dan pengambilan data intensitas radiasi berubah ubah setiap waktunya sebagai akibat dari adanya hambatan intensitas radiasi matahari yang diterima bumi seperti faktor kondisi atmosfer (cuaca, awan dan kecepatan angin), maka dalam pengambilan data setiap 15 menit sekali akan dihasilkan nilai perbedaan temperatur yang bervariasi sebagai akibat dari pengaruh hambatan intensitas radiasi matahari yang pengaruhnya juga berbanding lurus dengan temperatur permukaan bumi. Hal itu juga mempengaruhi oleh nilai resistansi termal atau hambatan panas yang terdapat dalam alat pemanfaatan panas buang atap seng. Hambatan panas tersebut terjadi pada proses perpindahan panas secara konveksi, konduksi dan radiasi pada masing-masing materialnya. Hal ini diperkuat oleh teori perpindahan panas terkait nilai hambatan panas tersebut, hambatan panas untuk dua jenis perpindahan panas adalah sebagai berikut:

$$
\text { Rth,Cond }=\frac{\Delta x}{K \cdot A} \text { dan Rth,Con }=\frac{1}{h \cdot A}
$$

Semakin besar nilai hambatan panas maka akan semakin kecil nilai perpindahan panas dari suatu sistem atau material.

Fenomena kedua yang terjadi yaitu pada gambar 5 dan Gambar 6 yang menjelaskan korelasi grafik terkait perbandingan antara beberapa temperatur seperti $T_{\text {hho }}$ dan $\mathrm{T}_{\text {hco }}$ dengan $\mathrm{T} \infty$. Fenomena yang terjadi adalah dimana semakin besar nilai temperatur lingkungan yang dipengaruhi oleh intensitas radiasi matahari maka nilai perbedaan temperatur tidak akan berubah bahkan semakin mengecil. Hal ini dikarenakan pada sisi dingin menggunakan fan dengan kecepatan udara yang dihasilkan sebesar $5 \mathrm{~m} / \mathrm{s}$ yang sumber udaranya berasal 
dari lingkungan, semakin tinggi intensitas radiasi matahari maka temperatur lingkungan akan meningkat dan menimbulkan efek meningkatkannya juga temperatur pada sisi dingin. Hal ini dapat dibuktikan dengan menggunakan rumus perpindahan panas secara konveksi yaitu:

$$
q=h \cdot A \cdot(T w-T \infty)
$$

Kedua fenomena tersebut yang menyebabkan daya listrik dan efisiensi pemanfaatan panas buat atap seng sangat kecil.

Gambar 7 menunjukan daya listrik yang dihasilkan dari proses pemanfaatan panas buang atap seng. Daya listrik yang dihasilkan mengacu pada perbedaan temperatur seperti yang ditunjukkan pada Gambar 4. Semakin besar nilai perbedaan temperatur yang dihasilkan antara area panas dan dingin, maka akan semakin besar daya listrik yang dapat dihasilkan.

\section{Simpulan dan Saran}

\subsection{Simpulan}

1. Energi panas buang atap seng terbukti dapat dimanfaatkan menjadi sumber energi listrik terbarukan.

2. Daya listrik dari hasil pemanfaatan energi panas buang yang dihasilkan selama 3 hari dari hasil penelitian rata rata adalah 0,0042 Watt. Efisiensi tertinggi yang didapatkan dari hasil pemanfaatan adalah $0,00888 \%$.

\subsection{Saran}

1. Dalam proses pemanfaatan panas buang pada alat simulasi yang menyebabkan nilai daya listrik dan efisiensi yang rendah adalah hambatan panas. Dengan kata lain, dalam penelitian selanjutnya diusahakan agar nilai hambatan panas dibuat seminimum mungkin.
2. Diperlukan pengganti heatsink sebagai media penyerap panas, dengan tujuan agar panas yang diserap lebih tinggi.

3. Untuk menghasilkan daya listrik yang besar, diperlukan nilai $\Delta \mathrm{T}$ yang besar. Oleh karena itu dibutuhkan media pendingin pada sisi generator termoelektrik sisi dingin dengan variabel lain.

\section{Kepustakaan}

[1] "Hotspot bukan berarti firespot, bisa jadi panas dari atap seng," Detik.com, Oct-2015.

[2] "Inilah cara meredam panas atap seng dengan sederhana," Pesonarumah.com, 2018.

[3] A. Pudjanarsa and D. Nursuhud, Mesin Konversi Energi, Edisi 3. Yogyakarta: ANDI, 2013.

[4] W. A. Nandar, Teknologi Rekayasa Surya. Jakarta: PT Pradya Paramita, 1995.

[5] C. Elango, N. Gunasekaran, and K. Sampathkumar, "Thermal models of solar still - A comprehensive review," Renew. Sustain. Energy Rev., vol. 47, pp. 856-911, 2015.

[6] M. Khalid, M. Syukri, and M. Gapy, "Pemanfaatan Energi Panas Sebagai Pembangkit Listrik Alternatif Berskala Kecil Dengan Menggunakan Termoelektrik," vol. 1, no. 3, pp. 57$62,2016$.

[7] A. Trisasmita and C. Rangkuti, "Potensi pemanfaatan sumber panas pada combustion chamber," pp. 7-14, 2017.

[8] M. Latif, N. Hayati, and U. G. S. Dinata, "Potensi Energi Listrik Pada Gas Buang Sepeda Motor," J. Rekayasa Elektr., vol. 11 , no. 5 , p. $163,2015$.

[9] D. Patil and R. R. Arakerimath, "A Review of Thermoelectric Generator for Waste Heat Recovery from Engine Exhaust," vol. 1 , no. 8, pp. 1-9, 2013.

[10] A. Jacks, D. Balaji, and D. Gowrishankar, "Waste heat energy harvesting using thermo electric generator," vol. 3, no. 7, pp. $1-4,2013$.

[11] M. G. Jadhav and J. S. Sidhu, "Design and Fabrication of Silencer Waste Heat Power Generation System Using Thermo-Electric Generator," vol. 7, no. 1, pp. 1-14, 2017.

[12] J. Holman, "Heat Transfer," Mc Graw Hill, 2010.

[13] B. Mismail, Rangkaian Listrik, Jilid Pert. Bandung: ITB Bandung, 1995.

[14] M. W. Zemansky and F. W. Sears, Fisika untuk Universitas 2 Listrik dan Magnet. Bandung: Binacipta, 1986. 